\title{
Agrowaste-based Polyhydroxyalkanoate (PHA) Production using Hydrolytic Potential of Bacillus thuringiensis IAM 12077
}

\author{
Vaishnavi Gowda and Srividya Shivakumar* \\ Department of Microbiology; Center for PG Studies; Jain University; Jayanagar - Bangalore
}

\begin{abstract}
The study identified the innate enzymatic potential (amylase) of the PHB producing strain B.thuringiensis IAM 12077 and explored the same for cost-effective production of PHB using agrowastes, eliminating the need for pretreatment (acid hydrolysis and/or commercial enzyme). Comparative polyhydroxyalkanoate (PHA) production by B. thuringiensis IAM 12077 in biphasic growth conditions using glucose and starch showed appreciable levels of growth $(5.7$ and $6.8 \mathrm{~g} / \mathrm{L}$ ) and PHA production (58.5 and $41.5 \%$ ) with a PHA yield of 3.3 and $2.8 \mathrm{~g} / \mathrm{L}$, respectively. Nitrogen deficiency supported maximum PHA yield $(2.46 \mathrm{~g} / \mathrm{L})$ and accumulation (53.3\%). Maximum growth $(3.6 \mathrm{~g} / \mathrm{L})$, PHB yield $(2.6 \mathrm{~g} / \mathrm{L})$ and PHA accumulation (72.8\%) was obtained with C:N ratio of 8:1 using starch as the carbon source $(10 \mathrm{~g} / \mathrm{L})$. Nine substrates (agro and food wastes) viz. rice husk, wheat bran, ragi husk, jowar husk, jackfruit seed powder, mango peel, potato peel, bagasse and straw were subjected to two treatments- acid hydrolysis and hydrolysis by innate enzymes, and the reducing sugars released thereby were utilized for polymer production. All the substrates tested supported comparable PHB production with acid hydrolysis $(0.96 \mathrm{~g} / \mathrm{L}-8.03 \mathrm{~g} / \mathrm{L})$ and enzyme hydrolysis $(0.96 \mathrm{~g} / \mathrm{L}-5.16 \mathrm{~g} / \mathrm{L})$. Mango peel yielded the highest PHB (4.03 $\mathrm{g} / \mathrm{L} ; 51.3 \%)$, followed by jackfruit seed powder $(3.93 \mathrm{~g} / \mathrm{L} ; 29.32 \%)$. Varied levels of amylase activity $(0.25 U-10 U)$ in all the substrates suggested the enzymatic hydrolysis of agrowastes.
\end{abstract}

Key words: Bacillus thuringiensis IAM 12077; Polyhydroxybutyrate; nutrient limitation; hydrolytic enzymes; mango peel

\section{INTRODUCTION}

Synthetic polymers (known as plastics) have become significant since the 1940 s, and since then they are replacing glass, wood and other constructional materials and even in many industrial, domestic and environmental applications. Their widespread application is due to their favourable mechanical and thermal properties in addition to their stability and durability (Ojumu et al. 2004). Its persistence in the environment leads to deleterious effects on wild life and greatly affects aesthetic qualities of the cities. The increased cost of solid waste disposal as well as the potential hazards from waste incineration such as dioxin emission from PVC makes synthetic plastic a waste management problem. Global focus is gradually turning away from synthetic polymers as a major source of raw material to polyhydroxybutyrate (a biodegradable polymer) for plastic and polymeric materials due to its biodegradability, environmental friendliness and ease of production from renewable resources (Muller et al. 2001; Ojumu et al. 2004).

*Author for correspondence: sk2410@yahoo.co.uk 
Biodegradable plastics are made from renewable resources and do not lead to the depletion of finite resources. A number of biodegradable plastic materials- mostly biodegradable polyesters, namely polyhydroxyalkanoates (PHAs), polylactides, aliphatic polyesters, polysaccharides, and the copolymers or blends of these, have been developed successfully to meet specific demands in various fields and industries (Ojumu 2004).

The production cost of commercially available polyhydroxyalkanoates is comparatively higher than that of conventional synthetic polymers (VanThuoc et al. 2007). This high cost of polymer production is the major bottleneck in the commercialization of biodegradable plastics. However, process economics reveal that the use of inexpensive and renewable carbon substrates such as agro-industrial wastes and by-products as feedstock can contribute to as much as $40-50 \%$ reduction in the overall production cost (Choi and Lee 1999; Kim and Chang 2000), and therefore can serve as a potential alternative to traditional carbon sources such as glucose (Hocking and Marchessault 1994; Steinbuchel and Fuchtenbusch 1998; Ojumu 2004). PHA can also be produced by fermentation using inexpensive raw materials, making its commercial production economically feasible (Oliviera et al. 2004; Sentil and Prabakaran 2006; Chariramjus 2008; Ramdas et al. 2009; Pal et al. 2009; Ghate et al. 2011). PHA production from wastes such as starch, whey, molasses, CSL, bagasse, soyameal, etc. can provide cost-effective as well as environmentally biodegradable polymer.

There are only a few reports on the use of starch by bacteria to produce PHA. Depending on the ability of the producing strain to amylolytically hydrolyze starch, starch can either be directly supplied as substrate, or after enzymatic, or chemical hydrolysis to its oligomers (maltotetraose, maltohexaose), dimers (maltose) and monomers (glucose). Ralstonia eutropha though produces $230 \mathrm{~g} / \mathrm{L}$ PHB from pure glucose lacks the ability to utilize starch, and thereby cannot produce PHB from alternative carbon source such as starch, or agro-wastes efficiently. However, $4 \mathrm{~g} / \mathrm{L}$ PHB has been obtained from $R$. eutropha using hydrolyzed starch. Van-Thuoc et al. (2007) reported that in order to use the agroindustrial residues as fermentation substrates, these should be subjected to hydrolysis for the release of easily metabolizable sugars. Acid and enzymatic methods are the two main reported methods for the hydrolysis, but acid hydrolysis requires more energy for heating and is relatively difficult to control. It also necessitates corrosion resistant materials since it gives rise to high color and salt and ash content. An economical process to hydrolyze the starch using the enzyme has scarcely been found.

The aim of the present study was to explore the potential of the strain B. thuringiensis IAM 12077 to produce PHB from starch, agro and food wastes using the innate enzymatic potential of the strain to overcome the pretreatment of substrates.

\section{MATERIALS AND METHODS}

Microorganism used in the study and PHB production under biphasic growth conditions

PHA accumulating Bacillus thuringiensis IAM 12077 (Pal et al. 2009) was used in this study. The strain showed capability to utilize a variety of mono and disaccharides, pentoses and hexoses for PHA production (Pal et al. 2009). It also produced appreciable levels of PHA from lactose and whey (Srividya 2011). Nutrient broth grown culture $(24 \mathrm{~h})$ of $B$. thuringiensis IAM 12077 was centrifuged at $8000 \times \mathrm{g}$ for $10-15 \mathrm{~min}$ and the culture pellet was transferred to $\mathrm{N}_{2}$ deficient medium ( $\mathrm{pH}$ 7.0) containing (g/L); 10 starch, 0.2 $\mathrm{MgSO}_{4}, 0.1 \mathrm{NaCl}, 0.5 \mathrm{KH}_{2} \mathrm{PO}_{4}, 2.5$ peptone, and 2.5 yeast extract (Mercan et al. 2002). Production studies were carried out in $250 \mathrm{~mL}$ flasks containing $50 \mathrm{~mL}$ culture medium and incubated at $37^{\circ} \mathrm{C}$ on a rotatory shaker at $120 \mathrm{rpm}$ for $48 \mathrm{~h}$. The PHA production in biphasic growth condition was performed with glucose and starch $(10 \mathrm{~g} / \mathrm{L})$ (Senthil and Prabakaran 2006).

\section{Extraction and determination of PHA}

After $48 \mathrm{~h}$ incubation at $37^{\circ} \mathrm{C}, 5.0 \mathrm{~mL}$ of the culture was taken and centrifuged at $8000 \mathrm{x}$ g for 15 min. The supernatant was discarded and the pellet was treated with $5.0 \mathrm{~mL}$ of sodium hypochlorite and incubated at $30^{\circ} \mathrm{C}$ for $2 \mathrm{~h}$. After incubation, the mixture was centrifuged at 10,000 $\mathrm{xg}$ for $15 \mathrm{~min}$ and then washed with distilled water, acetone, methanol for washing and extraction, respectively. Determination of PHA was performed by dry weight estimation where the pellet after extraction was dried to constant weight (Senthil and Prabakharan 2006). 


\section{Detection of hydrolytic enzymes}

Amylase was analyzed using starch plates and its activity in various agro-waste sources was measured as per standard protocol. The reducing sugar released was estimated by DNS method (Miller 1959).

\section{Optimization of growth and media conditions}

Detection of hydrolytic enzymes

Hydrolytic enzyme was estimated on starch plates and its activity in various agro-waste sources was estimated as per standard protocol.

\section{Time optimization}

The PHB production in biphasic growth condition was determined at various time intervals with $10(\mathrm{~g} / \mathrm{L})$ starch. PHB production as a function of time was determined in the second phase of growth with starch.

Media optimization (PHA production under various nutrient limiting conditions).

\section{Nitrogen}

A semi-defined PHA production medium, Kannan and Rehacek medium (Kannan and Rehacek 1970), was used with modification for the production of PHA under nitrogen-limiting conditions. The $\mathrm{pH}$ of the medium was adjusted to 6.8 before autoclaving. The medium contained (g/L) glucose 20; yeast extract, 2.5; $\mathrm{KCl}, 3.0$; $\left(\mathrm{NH}_{4}\right)_{2} \mathrm{SO}_{4}, 5.0$ and $100 \mathrm{~mL}$ of defatted soybean dialysate (prepared from $10 \mathrm{~g}$ of defatted soya bean meal in $1000 \mathrm{~mL}$ of distilled water for $24 \mathrm{~h}$ at $\left.4^{\circ} \mathrm{C}\right)$. The inoculum was prepared in $250-\mathrm{mL}$ Erlenmeyer flasks containing $30-\mathrm{mL}$ sterile nutrient broth. Flasks were incubated at $30^{\circ} \mathrm{C}$ for $24 \mathrm{~h}$ on a rotary shaker at $250 \mathrm{rev} / \mathrm{min}$. Ten milliliter of the seed culture was transferred into $50 \mathrm{~mL}$ sterile Kannan and Rehacek medium in $250 \mathrm{~mL}$ flasks, and incubated at $30^{\circ} \mathrm{C}$ under shaking condition (250 rev /min) (Kannan and Rehacek 1970). The cultures were harvested and assayed for PHA production at various time intervals.

\section{Potassium}

A previously reported potassium-deficient production medium (Wakisaka et al. 1982) was used for PHA production under potassiumdeficient conditions. The $\mathrm{pH}$ of the medium was adjusted to 6.8 before autoclaving. The medium contained $(\mathrm{g} / \mathrm{L})$ glucose 20; peptone 10; casein
$5.0 ; \mathrm{NaCl}$ 13. The inoculum was prepared as above and the inoculated production medium was used for $300 \mathrm{~mL}$ shaken flask cultures as described above.

\section{Sulphur}

Kannan and Rehacek medium (Kannan and Rehacek 1970) containing $8.0 \mathrm{~g} / \mathrm{L}$ ammonium chloride instead of the ammonium sulphate was used for PHA production under sulphur-deficient condition. The $\mathrm{pH}$ of the medium was adjusted to 6.8 before autoclaving. The inoculum was prepared as above and growth and production was monitored as described above.

\section{Phosphate}

A previously reported phosphate-deficient production medium (Rubia et al. 1986) was used for PHA production under phosphate-deficient conditions. The $\mathrm{pH}$ of the medium was adjusted to 6.8 before autoclaving. The medium contained (g/L) glucose, 20; potassium nitrate, 0.5; $\mathrm{MgSO}_{4} .7 \mathrm{H}_{2} \mathrm{O}, 0.2$; calcium chloride, 0.1 ; sodium chloride, 0.1. The medium also contained $(\mathrm{mg} / \mathrm{L})$ $\mathrm{K}_{2} \mathrm{HPO}_{4}, 8.0$ and $\mathrm{KH}_{2} \mathrm{PO}_{4}, 2.8$. The inoculum was prepared as above and the inoculated production medium was used for $50 \mathrm{~mL}$ shaken flask cultures as described above (Valappil et al. 2007).

\section{Effect of C: $\mathbf{N}$ ratio for PHB production}

This was actuated by varying ratios of carbon source (starch) with nitrogen (yeast extract) over a fixed range $(2: 1,4: 1,8: 1,10: 1$ and 20:1) to determine maximum PHA production.

\section{Evaluation of alternative carbon sources from agricultural and food waste}

Bacillus thuringiensis IAM 12077 culture grown in nutrient broth (24h) was centrifuged at $8000 \mathrm{x} \mathrm{g}$ for 10-15 $\mathrm{min}$ and the culture pellet was transferred to $\mathrm{N}_{2}$ deficient medium ( $\mathrm{pH}$ 7.0) containing $10(\mathrm{~g} / \mathrm{L})$ of the different carbon sources such as rice bran, wheat bran, bagasse, jack fruit seed, potato peel, mango peel, straw, ragi husk, jowar husk (procured from the local markets of Bangalore); yeast extract, $2.5 ; \mathrm{KCl}, 3 ;\left(\mathrm{NH}_{4}\right)_{2} \mathrm{SO}_{4}$, 5.0 and $100 \mathrm{~mL}$ of defatted soybean dialysate (prepared from $10 \mathrm{~g}$ of defatted soya bean meal in $1000 \mathrm{~mL}$ of distilled water at $4^{\circ} \mathrm{C}$ for $24 \mathrm{~h}$ ) (Kannan and Rehacek 1970). Production studies were carried out in $250 \mathrm{~mL}$ flasks containing 50 $\mathrm{mL}$ culture medium and incubated at $37^{\circ} \mathrm{C}$ on a rotatory shaker at $120 \mathrm{rpm}$ for $48 \mathrm{~h}$. 


\section{Pretreatment of agricultural and food wastes}

Two types of pre-treatment of the above mentioned agricultural and food wastes were carried out, viz. direct infusion and acid treatment. Direct infusion was carried out by drying and pulverizing the agricultural and food wastes. The powdered substrates were added as the sole carbon source and the media was supplemented with minimal salts $[(\mathrm{g} / \mathrm{L})$ yeast extract, $2.5 ; \mathrm{KCl}, 3.0$; $(\mathrm{NH} 4)_{2} \mathrm{SO}_{4}, 5.0$ and $100 \mathrm{ml}$ of defatted soya bean dialysate (prepared as mentioned earlier)]. All the agricultural and food waste substrates were hydrolyzed with $0.5-5.0 \% \mathrm{v} / \mathrm{v}$ sulphuric acid (solid: liquid, 1:10-1:20) and autoclaved at $121^{\circ} \mathrm{C}$ for $30 \mathrm{~min}$. The hydrolyzed samples were filtered and the supernatants were neutralized using sodium hydroxide $(6 \mathrm{~N})$. Reducing sugars content was determined by DNSA method (Ramdas et al. 2009). The media was prepared using these hydrolyzates at a concentration of $10 \%(\mathrm{v} / \mathrm{v})$. After autoclaving, $24 \mathrm{~h}$ old culture of B. thuringiensis IAM 12077 was inoculated in the modified media and incubated at room temperature for 48 to $72 \mathrm{~h}$ on shaker.

\section{Statistical analysis}

The mean and standard error was calculated from at least two independent experiments in duplicate. The analysis of variance was performed using SPSS version 20 statistical package and mean comparison were carried out using Duncan's multiple range test.

\section{RESULTS AND DISCUSSION}

Comparison of PHA production by $B$. thuringiensis IAM 12077 on glucose and starch

The strain showed amylase production on starch plate indicating its ability to utilize these complex carbohydrates. Hence, comparative PHA production by $B$. thuringiensis IAM 12077 was investigated in biphasic growth conditions using glucose and starch. Both the substrates showed appreciable levels of growth $(5.7$ and $6.8 \mathrm{~g} / \mathrm{L})$ and PHA production (58.5 and $41.5 \%$ ) with a PHA yield of 3.3 and $2.8 \mathrm{~g} / \mathrm{L}$, respectively (Fig. 1).

There are reports describing $25 \mathrm{~g} / \mathrm{L}$ of PHB when soluble starch was utilized as a carbon source with Azotobacter chroococcum in fed-batch mode (Kim 2007). PHB production by 11 different Bacillus sp. was studied by Chen et al. (1991), which showed a maximum of $50 \%(\mathrm{w} / \mathrm{v})$ PHB production on dry cell weight basis. In one study, 29 Bacillus strains were assessed for PHB production of which $B$. megaterium showed maximum production of $0.207 \mathrm{~g} / \mathrm{L}$ with productivity of $48.13 \%$. Lowest PHB reported was $6.53 \%$ in B. subtilis K1 (Aslim et al. 2002).

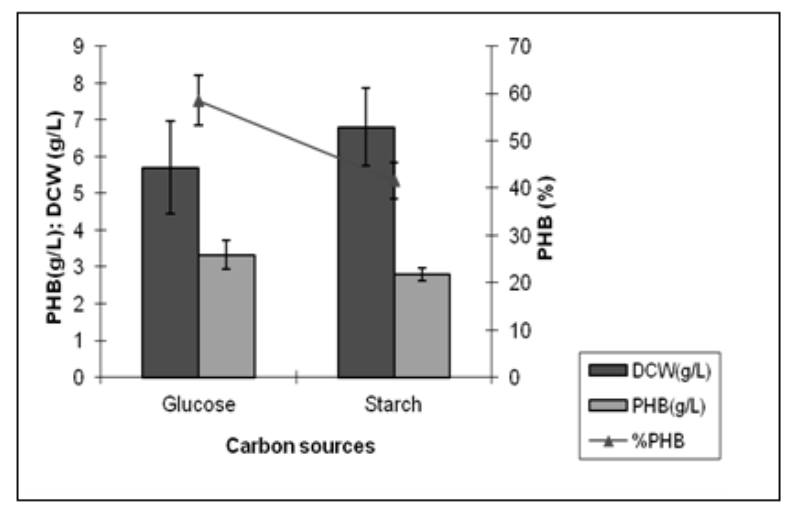

Figure 1 - Comparative PHA production between glucose $(10 \mathrm{~g} / \mathrm{L})$ and $\operatorname{starch}(10 \mathrm{~g} / \mathrm{L})$.

PHA production under growth limiting conditions

PHA production by B. thuringiensis IAM12077 under different culture conditions with limitation of potassium, nitrogen, sulphur and phosphate was investigated. In all the limiting conditions used, varied range of PHAs were produced with starch as carbon source $(10 \mathrm{~g} / \mathrm{L})$. Nitrogen deficiency supported maximum PHA yield $(2.46 \mathrm{~g} / \mathrm{L})$ and accumulation of PHB (53.3\%). However, sulphur deficiency though supported the highest cell biomass $(6.8 \mathrm{~g} / \mathrm{L})$, yielded only 1.4 $\mathrm{g} / \mathrm{L} \quad$ PHA, averaging $20.3 \%$ accumulation. Valappil et al. (2008) reported varied production of PHA by $B$. cereus SPV in different culture conditions with limitation of potassium, nitrogen, sulphur and phosphate. The nitrogen-deficient medium used in their study was by far the best medium in terms of both the cellular growth $(2 \mathrm{~g} /$ L) and PHA accumulation (38\% DCW), which was similar to the present observation. The authors also observed production of $\mathrm{P}$ (3HB-3HV) copolymer under the potassium limiting condition, using glucose as the carbon source, which was not studied in the present work.

\section{Effect of different C:N ratio for PHB production}

When tested for the growth and PHA accumulation by the strain using different ratios of 
$\mathrm{C}: \mathrm{N}$ ranging from $2: 1$ to $20: 1$, the maximum growth $(3.6 \mathrm{~g} / \mathrm{L})$, PHB yield $(2.6 \mathrm{~g} / \mathrm{L})$ and PHA accumulation $(72.85 \%)$ was obtained with $\mathrm{C}: \mathrm{N}$ ratio of 8:1, which was 1.9-folds higher in $\mathrm{PHB}$ yield and 1.66-folds increase in PHB accumulation as compared to a C:N ratio of 4:1 (Fig. 2). Further increase in $\mathrm{C}: \mathrm{N}$ ratio to $10: 1$ and $20: 1$ though showed an increase in cell biomass (3.6 to 5.2 $\mathrm{g} / \mathrm{L})$ caused a drastic reduction in PHB production (72.85 to $2.5 \%)$. This could be due to rapid utilization of excess carbon, leading to increased growth resulting in a change in the physiological status of the cells, which mimicked log phase rather than stationary, which was unfavorable for PHB production.

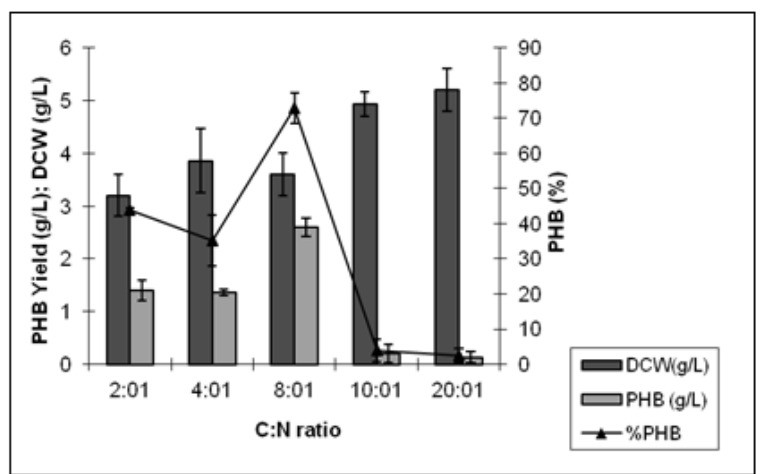

Figure 2 - Effect of different $\mathrm{C}: \mathrm{N}$ ratios on growth and PHA production using starch as carbon source under biphasic conditions.

\section{Evaluation of agro-industrial residues as carbon substrate}

For economical production, cheaper renewable sources, which are used as carbon feedstock and bacterial strains with the ability to produce large quantities of intracellular PHA utilizing such lowcost substrates are required. There is abundant availability of such waste generated in the agricultural sector and they are rich sources of carbohydrates. These wastes are mostly used as cattle feed since they have little economic value. Species of the genus Bacillus have the innate ability to utilize such diverse and cheap carbon wastes as they possess hydrolytic enzymes capable of metabolizing these complex residues. Therefore, native Bacillus strains are now being explored industrially using agro-wastes for economic PHA production.

Several studies have shown the utilization of various carbon sources by different bacterial strains. To confirm the feasibility of using agrowastes to replace glucose in the production of PHA by B. thuringiensis IAM 12077, dry cell weight and PHA accumulation was determined on different carbon sources (4\%, w/v) like bagasse, jowar, ragi husk, straw, rice husk, wheat bran, mango peel, jack fruit seed powder and potato peel residue in shake flask cultures. The strain showed PHB production on all the substrates tested (without pretreatment-direct infusion), which indicated its nutritional versatility and amylolytic potential (Fig. 3). The PHA yield and accumulation was highest with mango peel (4.03 $\mathrm{g} / \mathrm{L} ; 51.3 \%$ ), followed in the decreasing order by bagasse $(1.26 \mathrm{~g} / \mathrm{L} ; 46.15 \%)$; rice husk $(1.56 \mathrm{~g} / \mathrm{L}$; $32.7 \%)$; jackfruit seed powder (3.93 g/L; 29.32\%); ragi husk $(0.96 \mathrm{~g} / \mathrm{L} ; 23.2 \%)$, etc. All the substrates used supported amylase activity [data not shown]. The absence of correlation $(\mathrm{r}=-0.04768)$ between the levels of amylase activity and the PHB yield suggested the role of other enzymes such as cellulases (not determined) to also have played a role in the utilization of the substrates.

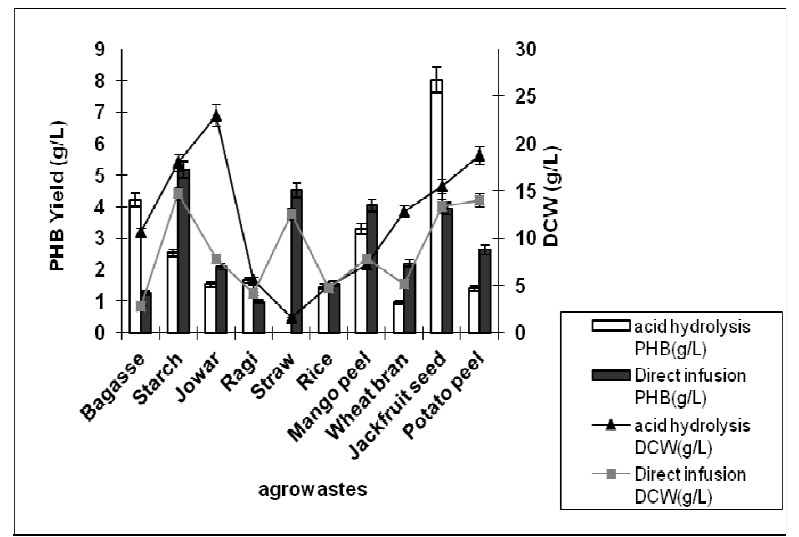

Figure 3 - Comparison of growth and PHA yields from agrowastes by different treatments (direct infusion and acid hydrolysis).

Acid hydrolyis of these substrates also supported PHB production by all the substrates, except straw (Fig. 3). Though straw hydrolysate supported the growth (1.6 g/L), no PHB production was observed. The PHB yield and accumulation was highest with jackfruit seed powder $(8.03 \mathrm{~g} / \mathrm{L}$; $51.7 \%$ ) followed in the decreasing order by bagasse $(4.2 \mathrm{~g} / \mathrm{L} ; 39.6 \%)$; mango peel $(3.3 \mathrm{~g} / \mathrm{L}$; $45.6 \%)$; ragi husk $(1.6 \mathrm{~g} / \mathrm{L} ; 29.6 \%)$ and rice husk $(1.46 \mathrm{~g} / \mathrm{L} ; 29.4 \%)$. Wheat bran, potato peel and jowar did not show comparable PHB 
accumulation (7.4, 7.4 6.6\%) on acid hydrolysis as in the case of direct infusion, though these substrates supported good biomass accumulation $(12.86,18.73,23.0)$. This could be attributed to these substrates being rich in protein, or other nutrients as well that triggered the growth phase instead of nutrient depletion. Similar observations were made by Van-Thuoc et al. (2007) and Ramadas et al. (2009) wherein wheat bran and cassava bagasse supported good growth but low PHB accumulation. There was a positive correlation between the amount of reducing sugar released [data not shown] by acid hydrolysis of the substrates with the PHB yield obtained $(\mathrm{r}=$ 0.70538).

On comparison of both these treatments (Fig. 3), it could be concluded that enzymatic hydrolysis of the substrates yielded appreciable levels of PHB (ranging from 0.966 in rice bran to $4.53 \mathrm{~g} / \mathrm{L}$ in straw) with almost all the agro-wastes used indicating the potential of exploiting the innate enzymatic ability of this strain and its nutritional versatility, which could make it a promising industrial PHB producer.

Several agro-industrial residues such as potato starch, babassu, soy cake (Oliveira et al. 2004) cane molasses, whey (Ahn et al. 2001) have been reported for PHB production. Fukui and Doi (1998) reported that the plant oils such as olive oil, corn oil and palm were good carbon substrates for $R$. eutropha for PHB production. Thakor et al. (2005) found the coconut oil as one of the best carbon source for Comamonas testosteroni. Rusendi and John (1995) used waste potato starch hydrolyzate for the production of PHB and reported a yield of $77 \%$ of the biomass dry weight. Ramadas et al. (2009) reported similar levels of PHB production in potato starch and jackfruit seed powder. Maximum production of $0.69 \mathrm{~g} / \mathrm{L}$ was obtained when a hydrolyzate prepared from $2 \%$ jackfruit seed powder was fermented at $30^{\circ} \mathrm{C}$ for $36 \mathrm{~h}$ in a medium containing nutrient salts and initial $\mathrm{pH}$ as 7.5 with $\mathrm{PHB}$ content in the cells amounting to $46 \%$.

Fermentation kinetics of PHB production by $B$. thuringiensis IAM 12077 on all different agrowastes substrates is depicted in Table 1 . Of the various agro-wastes tested, mango peel:YE (4:1) combination showed increased PHB yield and productivity $[\mathrm{PHB}(\mathrm{g} / \mathrm{L}), \mathrm{PHB}(\%)]$, with other parameters such as $\mathrm{Pp} / \mathrm{x} \quad \mathrm{g}_{\mathrm{PHB}} / \mathrm{g}_{\mathrm{DCW}}$ and $\mathrm{Qp}$
$\mathrm{gPHB} / \mathrm{CDW} / \mathrm{h}$ having higher values as 0.51 and 0.021 compared with other substrates.

Table 1 - Fermentation kinetics of B.thuringiensis IAM 12077 on different agrowastes (direct infusion).

\begin{tabular}{|c|c|c|c|c|}
\hline Parameters & Starch & $\begin{array}{c}\text { Mango } \\
\text { peel }\end{array}$ & Straw & $\begin{array}{c}\text { Jack } \\
\text { fruit seed } \\
\text { powder }\end{array}$ \\
\hline PHB g/L & 2.8 & $\begin{array}{c}4.03 \\
\text { (1.46 fold) }\end{array}$ & $\begin{array}{c}4.53 \\
(1.6 \text { fold })\end{array}$ & $\begin{array}{l}3.93 \\
(1.4)\end{array}$ \\
\hline DCW g/L & 6.8 & 7.86 & 12.56 & 13.4 \\
\hline${ }^{*} \mathrm{Qp} \mathrm{g}_{\mathrm{l} / \mathrm{h}} \mathrm{g}_{\mathrm{PHB}} /$ & 0.116 & 0.168 & 0.188 & 0.163 \\
\hline $\begin{array}{l}{ }^{*} \mathrm{Qx} \mathrm{g}_{\mathrm{DCW}} / \\
\text { 1/hr. }\end{array}$ & 0.3 & 0.16 & 0.18 & 0.16 \\
\hline${ }^{*} \mathrm{Yp} / \mathrm{s} \mathrm{g} \mathrm{g}_{\mathrm{PHB}} /[\mathrm{S}]$ & 0.07 & 0.1 & 0.113 & 0.1 \\
\hline $\begin{array}{c}{ }^{\pi} \mathrm{Yx} / \mathrm{S} \\
\mathrm{g}_{\mathrm{DCW}} /[\mathrm{S}]\end{array}$ & 0.17 & 0.19 & 0.31 & 0.33 \\
\hline $\begin{array}{c}{ }^{*} \mathrm{Pp} / \mathrm{x} \\
\mathrm{g}_{\mathrm{PHB}} / \mathrm{g}_{\mathrm{DCW}}\end{array}$ & 0.41 & 0.51 & 0.36 & 0.29 \\
\hline $\begin{array}{l}\text { PHB } \\
(\% \mathrm{DCW})\end{array}$ & 41.5 & $\begin{array}{c}51.3 \\
(1.23 \text { fold })\end{array}$ & 36 & 29.32 \\
\hline $\begin{array}{l}\text { Qp gPHB/ } \\
\text { CDW/hr. }\end{array}$ & 0.02 & 0.021 & 0.002 & 0.012 \\
\hline \multicolumn{5}{|c|}{$\begin{array}{l}\text { "Qp, Volumetric rate of polyhydroxybutyrate (PHB) formatio } \\
\left(\mathrm{g}_{\mathrm{PHB}} / \mathrm{l} / \mathrm{hr}\right) ; \\
\text { "Qx, volumetric rate of cell formation }\left(\mathrm{g}_{\mathrm{p}} / \mathrm{l} / \mathrm{h}\right) ; \\
\text { *Yp/s, PHB yield at the end of fermentation }\left(\mathrm{gPHB} / \mathrm{g}_{\mathrm{s}}\right) ; \\
\text { *Yx/s cell yield at the end of fermentation }\left(\mathrm{g}_{\mathrm{x}} / \mathrm{g}_{\mathrm{s}}\right) ; \\
\text { *Yp/x, PHB yield based on cells at end of fermentation }\left(\mathrm{g}_{\mathrm{PHB}} / \mathrm{g}_{\mathrm{x}}\right)\end{array}$} \\
\hline
\end{tabular}

\section{CONCLUSION}

Acid hydrolysis of the nine agro-wastes substrates showed jackfruit seed powder (2\%) as a promising substrate and supported maximum PHB production of $8.03 \mathrm{~g} / \mathrm{L}$ and $51.7 \%$ PHA accumulation in $48 \mathrm{~h}$ in a $\mathrm{N}_{2}$ deficient production medium and initial $\mathrm{pH}$ as 7.5. However, the innate enzyme hydrolyzate of mango peel was a good substrate for PHB production. Maximum production of $4.03 \mathrm{~g} / \mathrm{L}$ was obtained when a hydrolyzate prepared from $2.0 \%$ mango peel powder was fermented at $30^{\circ} \mathrm{C}$ for $48 \mathrm{~h}$ in a $\mathrm{N}_{2}$ deficient medium containing nutrient salts and initial $\mathrm{pH}$ as 7.5. The PHB content in the cells was $51.3 \%$, which was comparable to the yield obtained by acid hydrolysis of some of the substrates. The present study explored the potential of $B$. thuringiensis IAM 12077 to produce cost-effective PHB from alternate starch and agro-wastes using the innate enzymatic potential of the strain to overcome the pretreatment of substrates, which added to the cost of production. 


\section{REFERENCES}

Ahn WS, Park SJ and Lee SY. Production of poly (3hydroxybutyrate) from whey by cell recycle fed-batch culture of recombinant Escherichia coli. Biotechnol Lett. 2001; 23: 235-240.

Aslim B, Yuksekdag ZN and Beyatli Y. Determination of growth quantities of certain Bacillus Species isolated from soil. Turk J Biol. 2001; 24-30

Chaijamrus $\mathrm{S}$ and Udpuay $\mathrm{N}$. Production and characterization of polyhydroxybutyrate from molasses and corn steep liquor produced by Bacillus megaterium ATCC 6748. Agric Eng Int. 2008; 1-12

Chen GQ, Konig KH, Lafferty RM. Occurrence of poly-D(-)-3-hydroxyalkanoates in the genus Bacillus. FEMS Microbiol Lett. 1991; 84: 173-176

Choi J and Lee SY. Factors affecting the economics of poly-hydroxyalkanoates production by bacterial fermentation. Appl Microbiol Biotechnol. 1999; 51: 13-21

Fukui T and Doi Y. Cloning and analysis of the poly (3hydroxybutyrate- co- 3-hydroxyhexanoate) biosynthesis genes of Aeromonas caviae. J Bacteriol. 1998; 179: 4821-30.

Ghate B, Pandit P, Kulkarni C, Deepti D, Mungi and Patel TS. PHB production using novel Agroindustrial sources from different Bacillus sp. Int $J$ Pharm Bio Sci. 2011; 2(3): 242- 49

Hocking PJ, Marchessault RH. In: Griffin GJL, editor. Chemistry and technology of biodegradable polymers. London, UK: Blackie Academic \& Professional; 1994. P. 48-96.

Kannan LV and Rehacek Z. Formation of poly-bhydroxybutyrate by actinomycetes. Ind $\mathrm{J}$ Biochem. 1970; 7: 126-129.

Kim BS and Chang HN. Control of glucose feeding using exit gas data and its application to the production of PHB from tapioca hydrolysates by Alcaligenes eutrophus. Biotechnol Tech. 2000; 9: 311-314.

Kim DY, Kim H, Chung $\mathrm{MH}$ and Rhee YH. Biosynthesis, Modification and Biodegradation of Bacterial medium chain length polyhydroxyalkanoate. J Microbiol. 2007; 45(2): 8797

Mercan N, Aslim ZN, Yukesekdag and Beyatli Y. Production of PHB by some Rhizobium. Turk J Biol. 2002; 26: 215-219.

Miller GL. (1959), Use of Dinitrosalicylic acid reagent for determination of reducing sugar. Anal Chem. 1959; 31: 426-428.
Muller RJ, Kleeberg I and Deckwer WD. Biodegradation of polyhydroxybutyrates. Bioengineering. 2001; 19: 9-17.

Ojumu TV, Yu J and Solomon BO. Production of polyhydroxyalkonoates, a bacterial biodegradable polymer. Afr J Biotechnol. 2004; 3: 18-24.

Oliviera, FC, Freire DMG and Castilho LR. Production of poly (3- hydroxybutyrate) by solid-state fermentation with Ralstonia eutropha. Bioresource Techno.l 2004; 25: 65-70.

Pal A, Prabhu A, Kumar AA, Rajgopal B, Dadhe K, Ponamma V and Shivakumar S. Optimization of process parameters for maximum Poly (- $\beta$-)hydroxybutyrate (PHB) production by Bacillus thuringiensis IAM12077. Pol J Microbiol. 2009; 58: 149-154.

Ramadas NV, Singh KS, Soccol RC and Pandey A. Polyhydroxybutyrate production using Agroindustrial residue as substrate by Bacillus sphaericus NCIM 5149. Braz Arch Biol Technol. 2009; 52(1): 17-23.

Rubia TDL, Lopez JG, Ballesteros F and Cormenzana AR. Growth of Bacillus megaterium in phosphate limited medium. Folia Microbiol. 1986; 31: 98-105.

Senthil KB and Prabakaran G. Production of PHB (bioplastic) using bio-effluent as substrate by Alcaligens eutrophus. Ind J Biotechnol. 2006; 5: 7679.

Srividya S. Production of PHB from lactose and whey by Bacillus thuringiensis IAM 12077. Res J Biotech. 2011; 6(4): 12-18.

Steinbüchel A and Füchtenbusch B. Bacterial and other biological systems for polyester production. Trends Biotechnol. 1998; 16: 419-27.

Valappil SP, Rai R, Bucke C and Roy I. Polyhydroxyalkanoate biosynthesis in Bacillus cerus SPV under varied limiting conditions and an insight into the biosynthetic genes involved. $J$ Appl Microbiol. 2008; 104:1624-1635.

Van-Thuoc D, Quillaguaman J, Mamo G and Mattiasson B. Utilization of agriculture residues for poly (3-hydroxybutyrate) production by Halomonas boliviensis LC1. J Appl Microbiol. 2007; 104: 420428.

Wakisaka Y, Masaki E and Nishimoto Y. Formation of $\delta$-endotoxin or poly-b-hydroxybutyric acid granules by asporogenous mutants of Bacillus thurungiensis. Appl Environ Microbiol. 1982; 43: 1473-1480.

Received: November 02, 2012; Accepted: : November 25, 2013 